\title{
VEGETATION MONITORING BY REMOTE SENSING TECHNOLOGY FOR UNINHABITED ISLANDS OF THE XISHA ISLANDS
}

\author{
L. $\mathrm{Li}^{1,2, *}, \mathrm{Y} . \mathrm{Guo}^{2}, \mathrm{X} . \mathrm{Wu}^{1}$ \\ ${ }^{1}$ China Aero Geophysical Survey \& Remote Sensing Center for Land and Resources, Beijing, China - lileey2010@163.com \\ ${ }^{2}$ China University of Geosciences (Beijing), Beijing, China - gy939251@163.com
}

Commission III, WG III/7

\begin{abstract}
KEY WORDS: the Xisha Islands, Remote Sensing, Uninhabited Island, Vegetation Remote, Vegetation Monitoring, Island Development
\end{abstract}

\begin{abstract}
:
The Xisha islands are tropical coral islands in the south sea of China, with special ecological environment. As far away from the inland, they are more sensitive to climate change than inland, and are looked as the window to reflect global environment changes. Since Sansha city established, some of islands were developed. The uninhabited islands are decreasing. To discover the changes of uninhabited islands become more impending. In order to find out the natural status of uninhabited islands, monitoring four years vegetation change of 2002, 2010, 2013 and 2016. In addition, monitoring the typical uninhabited island and sandbar vegetation by making the most of existed high resolution remote sensing data, nine years from 2002 to 2013 and six months in 2012. The results show that the sandbars are in stable growth stage, especially after 2010, the vegetation start appeared. Meanwhile, analysis the vegetation variation of the uninhabited islands and sandbars.
\end{abstract}

\section{INTRODUCTION}

The Xisha islands are tropical coral islands lies in the southeast of Hainan province. The northern latitude is between $15^{\circ} 40^{\prime} \sim$ $17^{\circ} 10^{\prime}$, and the east longitude is between $111^{\circ} 11^{\prime} \sim 113^{\circ} 00^{\prime}$. Although the area of coral island is small, they are more characteristic than normal islands in vegetation dynamics and ecological series. As far away from the inland, they are unavailable for animal and plant exchange from outside. That is why those islands are more sensitive and more likely affected by the climate. Scientists look those islands as the window to reflect global environment, which are sensitive to the environmental change (Liu et al., 2007a).

Since Sansha city established, some of islands were developed. The uninhabited islands are decreasing. To discover the changes of uninhabited islands become more impending. There are several researches in the Xisha islands survey about soil, ecological environment, drillig, groundwater and biological survey before the Sansha city established. But lack of vegetation monitoring for recent years. In order to find out the natural status of uninhabited islands, based on the Territorial Survey project of China Geological Survey "Integrated Remote Sensing Survey for the Sansha islands and reefs (2013 to 2016)", carry out the Xisha islands uninhabited islands and sandbars vegetation monitoring from 2002 to 2016 by high resolution remote sensing data. Considering the study islands shoreline change result and the south china sea level change data in recent years, to discover the ecological status of the Xisha islands.

Limited by the satellite data, besides the whole uninhabited islands and sandbars four times monitoring, chose the south sandbar and the middle island with the most number of satellite data, as the typical study area for another nine years and six months monitoring. For all the uninhabited islands and sandbars are very near to each other, up to five kilometers, the vegetation environment is the same. The result of their vegetation change can reflect the total uninhabited islands and sandbar of the Xisha islands.

\section{GENERAL SITUATION OF THE STUDY AREA}

There are total nine islands and sandbars inhabited in the Xisha islands. They are the middle island, the south island, the north sandbar, the middle sandbar, the south sandbar, the new western sandbars that lies in the Xuande Islands, and Yinyu, Shiyu lies in the Yongle islands. As Yinyu, Shiyu and the new western sandbar have no vegetation at all, we take the other seven inhabited islands and sandbars as the study area.

Given the existed satellite data, take four monitoring for the study area, which include $2002,2010,2013$ and 2016. The satellite data are most shoot on dry season in order to reduce the impact by the rainfall of different seasons. In addition, choose the middle island and the south shale whose satellite data are available to carry out annual and seasonal change monitoring as the typical study area.

The study area lies in the north of the Xisha islands, as part of Qilianyu. All the islands and sandbars are within five kilometers which is very near to each other. The middle island and the south island have high vegetation coverage, with the main plant of Yangiiao tree, about one and a half meter high. The other sandbars have few shrub, no less than half meter high. 
Among those inhabited islands, mainly introduce the south shale and the middle island as the typical study area. The middle island lies in the north of the south shoal. All the island is cover by plant, except the beach, 700 meters long and 250 meters wide. The area is about 0.2 square kilometers. All round is higher than the middle, with 6 meters elevation. There is sand berm around the island with 60 meters wide and 4 meters high. There developed beach rock outside of the sand berm.

The south sandbar lies in the utmost south part of Qilianyu, with the shape of scalene triangle. The utmost length is the side of north-southern direction, about 500 meters. The widest side is about 300meters. Its area is 0.06 square kilometers, with elevation 4.1 meter. All round is higher than the middle of the shale. There are beach rock in the north and east-southern side. The other side is fine sand beach with coral and shell debris. The soil is phospho calcic soil for the sake of bird droppings. The vegetation is bushes and shrubs. The study islands and sandbars image show as Figure 1.

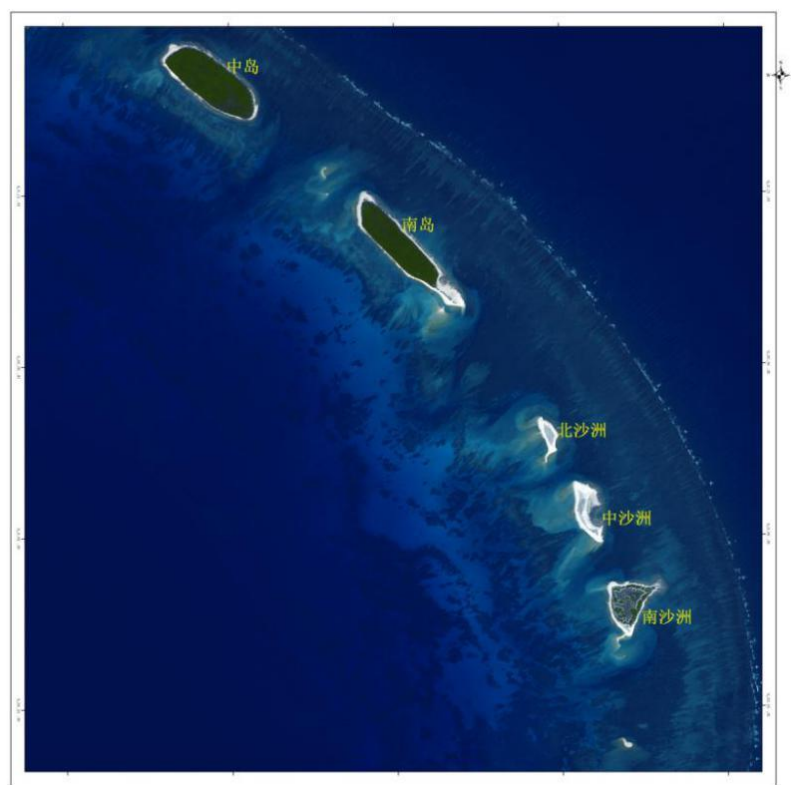

Figure 1. the Study Area

\section{DATA SOURCE}

All the satellite data's spatial positioning accuracy is within one meter. The data include QuickBird, WorldView2, GeoEye, and GF2. The data processing include image registration and image fusion. As for the total uninhabited islands vegetation monitoring, the four monitoring data are 2002, 2010, 2013 and 2016. According to the existed satellite data, only the middle island and the south sandbar have enough existed data to carry out seasonal and annual vegetation analysis.

There are two seasons in the Xisha islands. The dry season is from December to May, and the rainy season is from June to October. According the historical satellite data, there are the most satellite data in 2012 which are February, May, June, September, October, November of 2012. So chose all the six months data of 2012 for vegetation seasonal change analysis. While the annual monitoring is about seven years of 2002, 2007, 2008, 2009, 2011, 2012 and 2013. All the satellite data is show in Table 1.

\begin{tabular}{|l|l|l|l|}
\hline No. & Data type & Time & The study area \\
\hline 1 & Quick-Bird & 20020731 & The uninhabited islands \\
2 & WorldView2 & 20100207 & and sandbars \\
3 & WorldView2 & 20130428 & \\
4 & GF2 & 20160108 & \\
\hline 5 & Quick-Bird & 20020731 & The middle island and \\
6 & Quick-Bird & 20030615 & the south sandbar \\
7 & Quick-Bird & 20070526 & \\
8 & Quick-Bird & 20080110 & \\
9 & Quick-Bird & 20090302 & \\
10 & WorldView2 & 20100207 & \\
11 & WorldView2 & 20110505 & \\
12 & WorldView2 & 20120226 & \\
13 & WorldView2 & 20130428 & \\
\hline 14 & WorldView2 & 20120226 & The middle island and \\
15 & Quick-Bird & 20120502 & the south sandbar \\
16 & Quick-Bird & 20120627 & \\
17 & WorldView2 & 20120924 & \\
18 & Quick-Bird & 20121020 & \\
19 & WorldView2 & 20121114 & \\
\hline
\end{tabular}

Table 1. Satellite data list

\section{THE RESULT AND ANALYSIS}

\subsection{Four monitoring for the uninhabited islands and sandbars}

In order to discover the vegetation growth direction, circle the vegetation boundary area on the image. The vegetation boundary coverage increased $10991.61 \mathrm{~m}^{2}$ from 2002 to 2016 , by $5.5 \%$. And the growth rate is about $845 \mathrm{~m}^{2} / \mathrm{a}$. The growth rates vary by time. From 2002 to 2010 , the growth rate is about $628 \mathrm{~m}^{2} /$ a. From 2010 to 2013 , some vegetation destroyed by natural factors, about $5472 \mathrm{~m}^{2}$ vegetation disappeared. However, from 2013 to 2016, the vegetation grows quickly, increased about $12063 \mathrm{~m}^{2}$, the growth rate is $4021 \mathrm{~m}^{2} / \mathrm{a}$. The vegetation change for the islands and sandbars in the study area is shown as Figure 2.

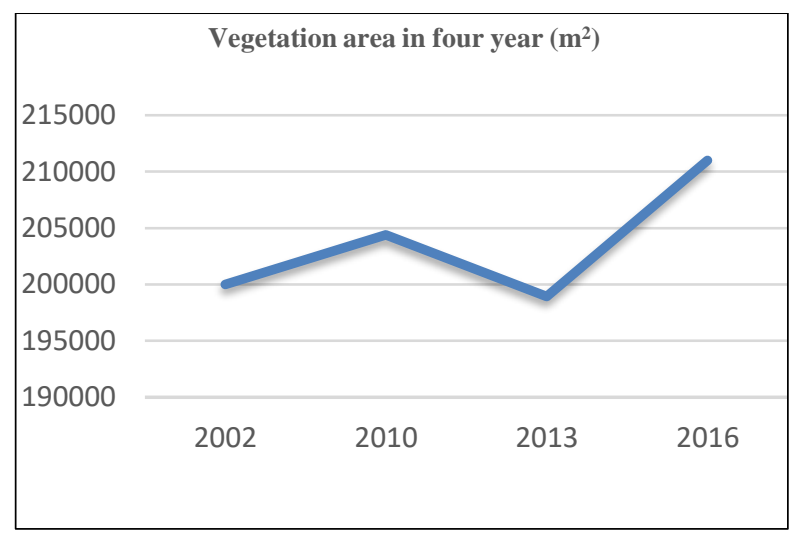

Figure 2. the Uninhabited Islands and Sandbars Vegetation Change (2002 2016)

Sandbars and the sand mouth of islands are the main places where vegetation changes. As shown from Figure 3, the vegetation on the sand mouth increased from 2002 to 2010 , but decreased till 2013. And from 2013 to 2016, the vegetation grew again. For two islands, the vegetation increased mainly on the sand mouth, where has few plant on 2002. For the sandbars, the vegetation change is obvious and visual. The vegetation on 
the north sandbar and the middle sandbar have gone from nothing to more, which is show as Figure 4. As the middle sandbar the example, there is no plant till 2010. Few of shrub appeared on the middle and south of the sandbar. From 2013 to 2016, the shrub grows faster than before, and all over the sandbar, which can be seen from Figure 5 the contract picture of 2013 and 2016.

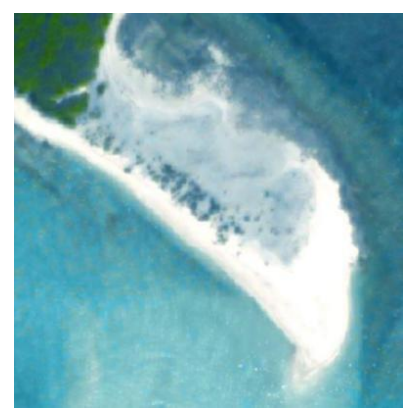

South Island in 2002

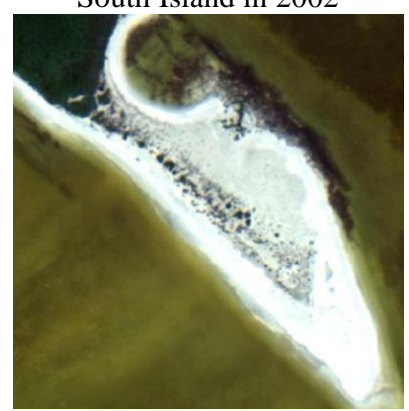

South Island in 2013

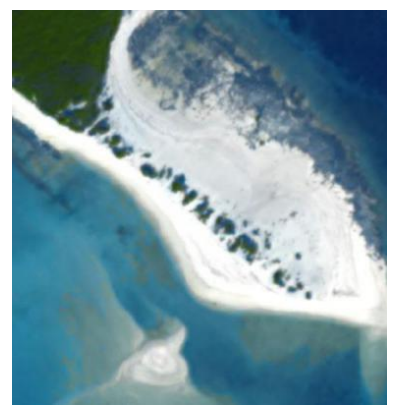

South Island in 2010

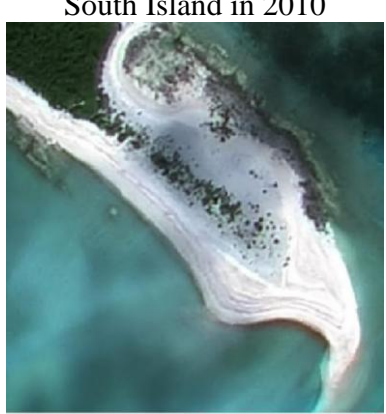

South Island in 2016
Figure 3. the Sand Mouth Plant Growth in South Island (2002 2016)

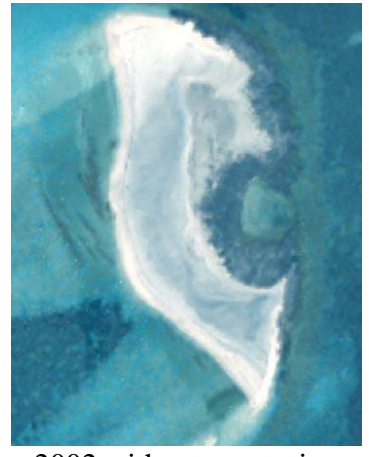

2002 without vegetation

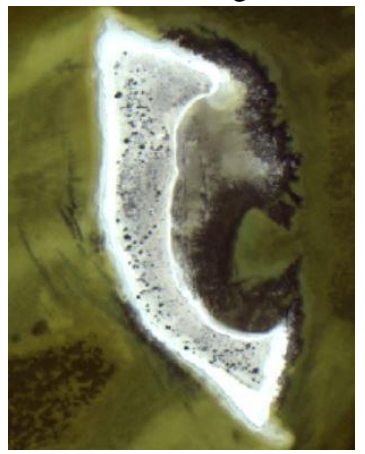

The middle sandbar in
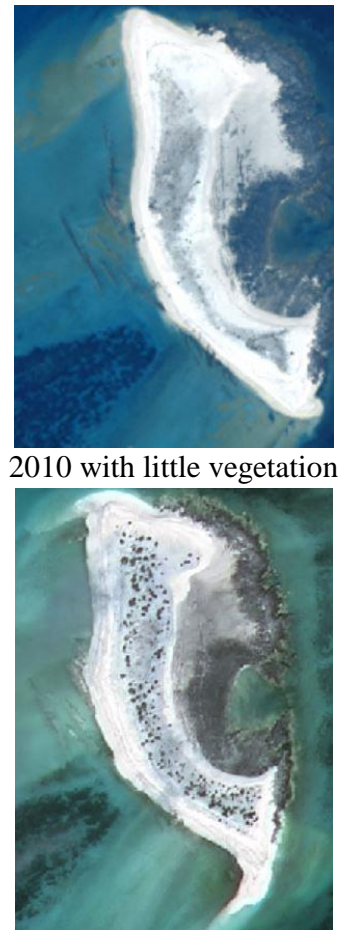

The middle sandbar in 2016
2013

Figure 4. the Middle Sandbar (2002 2016)

The vegetation boundary area increase means the vegetation boundary extended. As mentioned above, most of those islands height is under five meters, so the change of global sea level can bring great effect on those islands. The plant cannot grow if soaked by sea water.

As the survey result of coastline between those years, the coastline change trend is shown at Figure 5. The coastline decreased from 2002 to 2010, and it increased from 2010 to 2013. From 2013 to 2016, it decreased again. As the data of south sea level height by Sheng Fang (Sheng et al., 2016), the sea level height is increased from 2002 to 2009, and decrease from 2010 to 2013, which is in accordance with the trend of coastline.

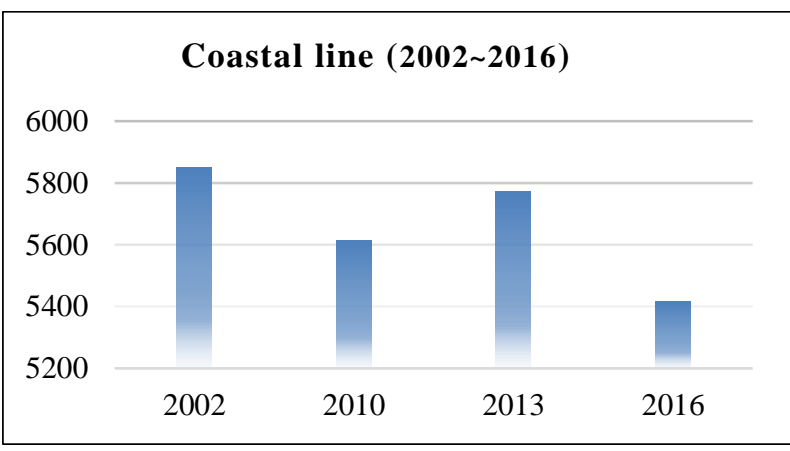

Figure 5. the coastal line change (2002 2016)

When the sea level rise, the coastline decrease. The area for the vegetation growth decrease too. But the result show that the vegetation area is not in accordance with the coastline change. Above the coastline, there is enough space for the vegetation growth. And the vegetation grew toward the islands and sandbars centre, not toward the ocean.

The vegetation was increased in the past ten years, except the period between 2010 and 2013. By the weather information, there were six typhoons and super storm from 2011 to 2013 in the south sea. Especially three super storm in 2011 and 2 typhoons in 2013, which destroyed the vegetation in the study area. After 2013, no typhoon and super storm were passed through the south sea. By the adequate precipitation brought by the past super storm, it is more available for the vegetation growth.

\subsection{Vegetation monitoring for the typical place}

In order to discover more details about the vegetation change, carry out eight years of vegetation monitoring for the typical place of the middle island and the south sandbar. As show by the Figure 6, the vegetation coverage increased year by year from 2002 to 2013, which totally increased about $63 \mathrm{~m}^{2}$ in the past ten years. The growth rates begun to increase after 2010 , which increased from $2 \mathrm{~m}^{2} / \mathrm{a}$ to $17 \mathrm{~m}^{2} / \mathrm{a}$. 


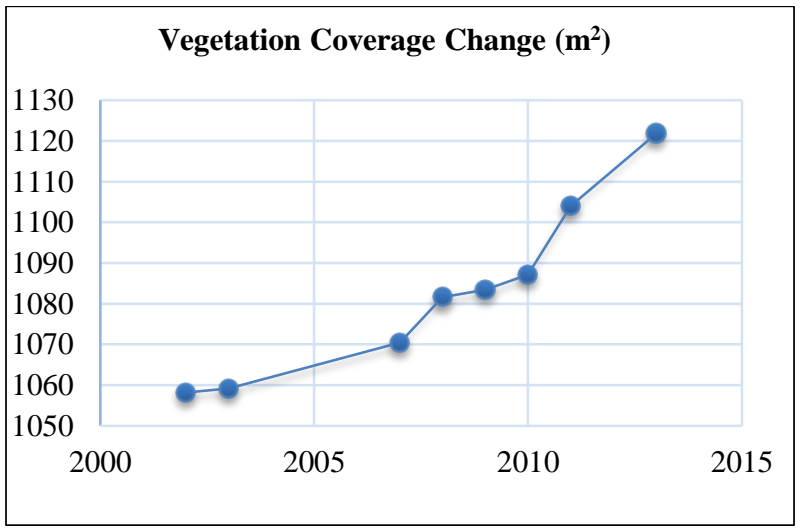

Figure 6. the Typical Island and Sandbar Vegetation Change

As shown by the Figure 7, the seasonal monitoring is from February to November of 2012. The vegetation maintains overall growth trend, and increased $38 \mathrm{~m}^{2}$ from February to November. As mentioned above, the rainy season in the Xisha islands is from June to October. While the dry season is from November to May. The monitoring results shows that the vegetation in rainy season increased $26 \mathrm{~m}^{2}$, and in the dry season increased $17 \mathrm{~m}^{2}$. It shows that the vegetation in rainy season grew faster than the dry season. But there has no evidence to prove that the vegetation will increase during the whole rainy season and will decrease in the whole dry season. From the Figure 7, the vegetation keeps overall growth trend, even in the dry season. The water supply for the vegetation growth not only by atmospheric precipitation, but also by the groundwater. The vegetation growth reflect that the sandbar has enough ground water to support the vegetation during the dry season in 2012.

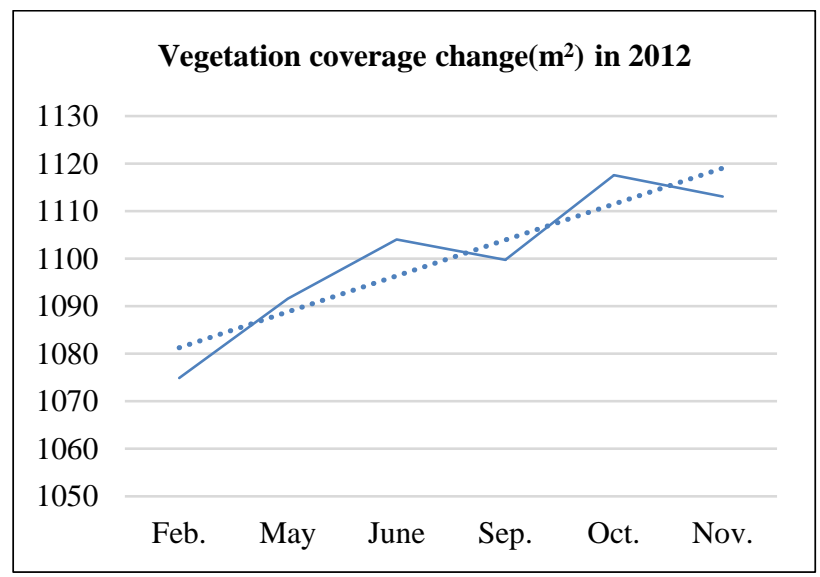

Figure 7. the typical island and sandbar vegetation change in 2012

\section{CONCLUSION}

(1) The vegetation in the uninhabited islands and sandbars of the Xisha islands keep stable growth trend in the past ten years. The growth rates begun to increase after 2010, and the sandbar has enough ground water to support the vegetation during the dry season.

The reasons for vegetation growth are warm temperature, proper rainfall and water-storing soil. Thanks for the climate data from china meteorological net, during the period of 2002 and 2016, the Xisha island has long hours of sunshine, and the sum hours reach 2940 hours per year. The whole year's high temperature is very helpful for the growth of plant. No extreme weather appeared to affect plant growth, whether the extreme high-temperature or extreme low-temperature. The typhoon in the rainy season had brought plenty of rainfall, which is very good for vegetation growth. According the drilling data, there is dense bird dung layer under the soil, which can storing fresh water.

(2) Sandbars and the sand mouth of islands are the main places where vegetation changes. The vegetation in sandbars is more sensitive than the islands, as the vegetation coverage of the islands were very high already. While the sandbars had little vegetation before 2002. For example, the north sandbar and the middle sandbar has no vegetation at 2002, and there were some plant grow out till 2010. Among the typical study islands, the vegetation growth in the south sandbar is far more better than the middle island. So if the condition for vegetation growth is available, the sandbars have more room for growth.

\section{REFERENCES}

Fang, S., et al., 2016a. Analysis and Comparison of the Sea Level Rising Trend in the Marginal Seas around China. Climatic and Environmental Research, 21(3), pp. 346-356.

Fuwu, X., et al., 1993a. Investigation of plant resources in Xisha Islands, Journal of plant resources and environment, 2(3), pp. 1-6.

Hongda, Z., et al., 1974a. The Vegetation of the HSI-SHA Islands. ACTA BOTANICA SINICA, 16(3), pp. 183-190.

Li, L., et al., 2014. The Coastline Remote Sensing Survey for Zhaoshu Island in Xisha Islands based on WorldView2. International Symposium on Optoelectronic Technology and Application 2014: Infrared Technology and Applications, Vol 929904, pp.1-6.

Li, L., et al., 2017a. A Comprehensive Survey of Remote Sensing in Xisha Islands. Geology Press, ISBN 978-7-116-10501-0.

Liguang, S., et al., 2005a. An Eco-Environmental Report on Xisha Archipelago of South China Sea. Review Article Chinese Journal of Nature, 27(2), pp. 79-84.

Xiaodong, L et al., 2007a. Eco-environment response to climate changes on Dongdao Island of South China Sea over the past 1300 years. Journal of University of Science and Technology of China, 37(8), pp. 1010-1016.

Yi, T., et al., 2013a. Vascular plant diversity of the Paracel Islands, China. Biodiversity Science, 21(3), pp. 364-374. 